\title{
Experience: An Oil Spill from a Crude Oil Pipeline
}

\author{
Huseyin Murat Cekirge \\ Department of Mechanical Engineering, the Grove School of Engineering, the City College of the City University of New York, New York, \\ USA
}

\section{Email address:}

hmcekirge@usa.net

\section{To cite this article:}

Huseyin Murat Cekirge. Experience: An Oil Spill from a Crude Oil Pipeline. International Journal of Environmental Monitoring and Analysis. Special Issue: Environmental Social Impact Assessment (ESIA) and Risk Assessment of Crude Oil and Gas Pipelines.

Vol. 3, No. 6-1, 2015, pp. 56-65. doi: 10.11648/j.ijema.s.2015030601.17

\begin{abstract}
This paper introduces an oil spill scenes from a crude oil pipeline. The oil spill is presented in a short narrative, however a series of pictures taken from the accident sites were included in the paper. The pictures are in the time order of events during the accident. The ferocity of the events can be seen and followed through pictures. The paper creates and provides the sense and understanding of oil spills to the researcher working in this field.
\end{abstract}

Keywords: Oils Spills from Crude Oil Pipelines Rupture of a Crude Oil Pipeline, Cleaning Oil on the Shorelines, Use of Oil Booms, Oil Debris Storage, Fishnetted Boom, Usage of Booms

\section{Introduction}

There are abundance of papers on oil spills; discussing oil spill transport modelling, risk analyses, ESIA (Environmental and Social Impact Assessment), behavior of oil land and in marine areas, and other related problems of oil spills, [1 - 10]. In this paper, an actual oil spill from a crude oil pipeline is introduced and presented through photographs. A spill accident was happened by ruptured the 18 -inch crude oil pipeline. An oil spill of almost 40000 barrels gushed into a dam lake in a land locked area. The spill was very unusual oil spill since, it was not a land spill or a marine spill or a lake spill. It was spill of dam lake spill and very crucial; since the water is being use for irrigation and domestic purposes.

The accident was happened by rupturing 18 -inch crude oil pipeline, which previously was removed from the lake area to prevent accidents. The rupturing was happened during earthwork activities, most likely there was a hit from a backhoe, Figures 1-2. Then, oil flowed through an irrigation channel from the ruptured pipeline to the lake. The pipeline administration was not prepared such an event and there were not appropriate equipments in the area. The cleaning crews tried to recover oil by equipments that they could acquire from the local sources. The modern equipment arrived in the area within a week, and modern recovery was initiated and completed.

The area was very fragile and shorelines were cleaned up by hand labor and the collected debris was stored local and outside storage areas. At the end 25000 barrels of oil was collected; the rest is recovered and taken from water and shorelines.

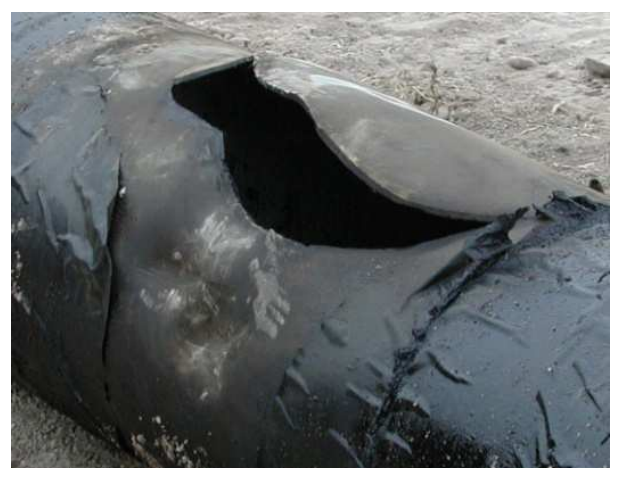

Figure 1. Ruptered pipeline, [11] and [12].

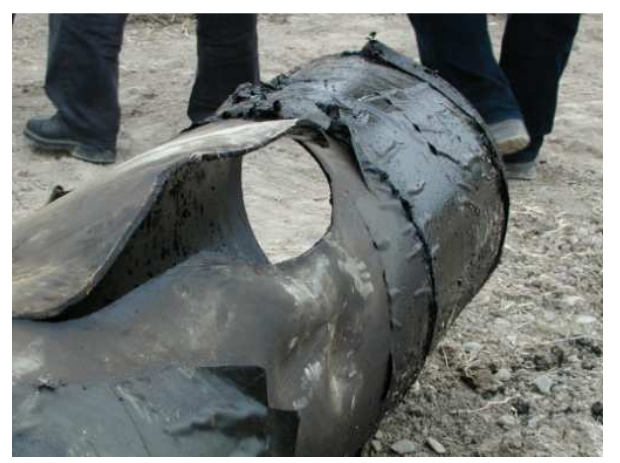

Figure 2. Another view of ruptured pipeline, [11] and [12]. 
Some light volatiles dissolved in water might end up downstream, however the dam lake is a very large water body; and the influence on the agriculture was extremely minimum.

A fishnetted booms were prepared and used to recover the oil from the water, [11]. Under these circumstances, every possibility and capacity was used to protect the environment. The pictures are from an archive, [12].

\section{Analysis of the Response}

\subsection{Source of the Oil Spill}

The oil spill started from a ruptures pipeline during earth works in the area. The spilled oil found its way to the dam lake through an irrigation channel used for adjacent agricultural areas. Unfortunately, the shutting down the valves were delayed around six or seven hours, Figures $3-8$. The channel was located, closed and boomed to prevent further flow of oil from the ruptured pipeline. The pipeline is repaired for oil transportation from the oil field. The accident was happened in a remote area, a trailer was furrnished as a command room for IC (Incident Command) operations, Figures $9-10$. The movements of oil was observed bu using three percent law of oil spill movements on water; and the wind vector was obtained from local authorities and/or guessed by looking at local conditions for deployment of manpower and equipment. There was no computer realated help at beginning.

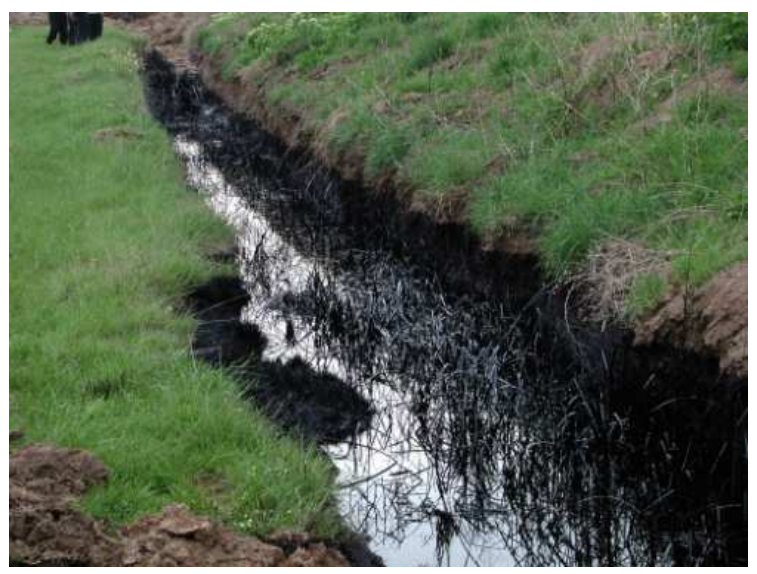

Figure 3. Irrigation channel, [11] and [12].

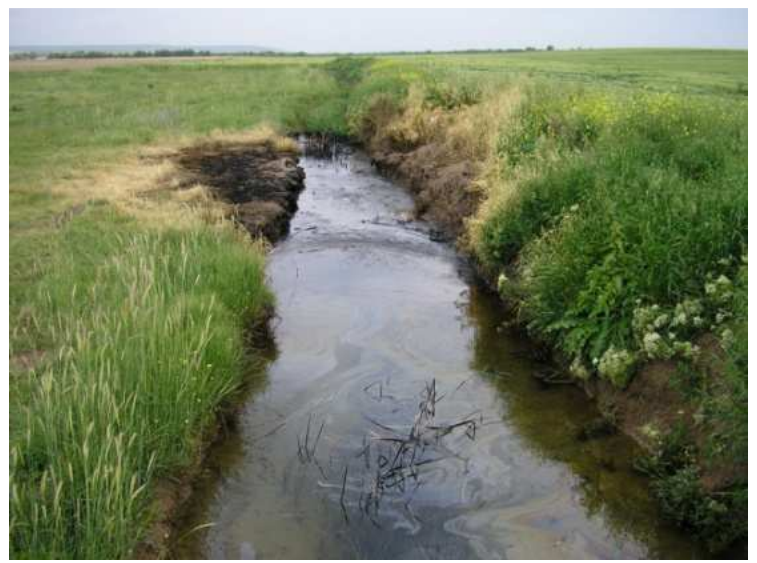

Figure 4. Oil flowing through the irrigation channel, [11] and [12].

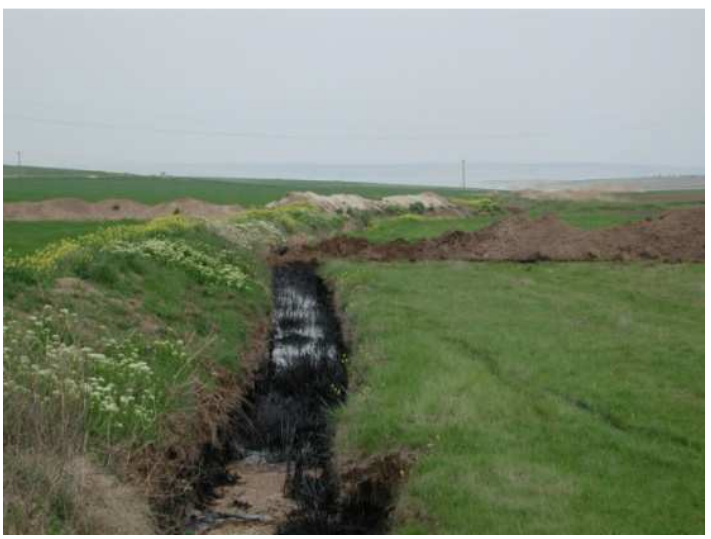

Figure 5. Another view of the irrigation channel, [11] and [12].

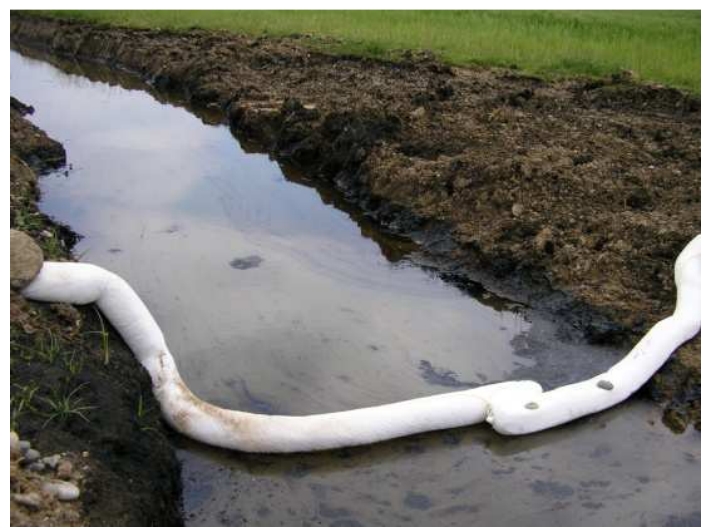

Figure 6. Boomed channel, [11] and [12].

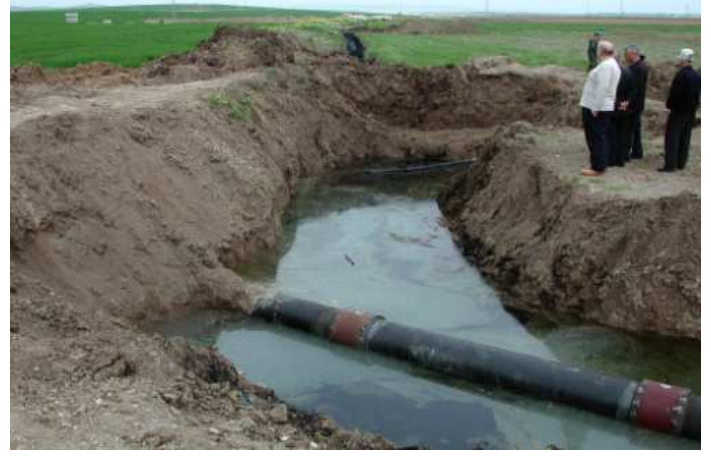

Figure 7. Repaired pipeline, [11] and [12].

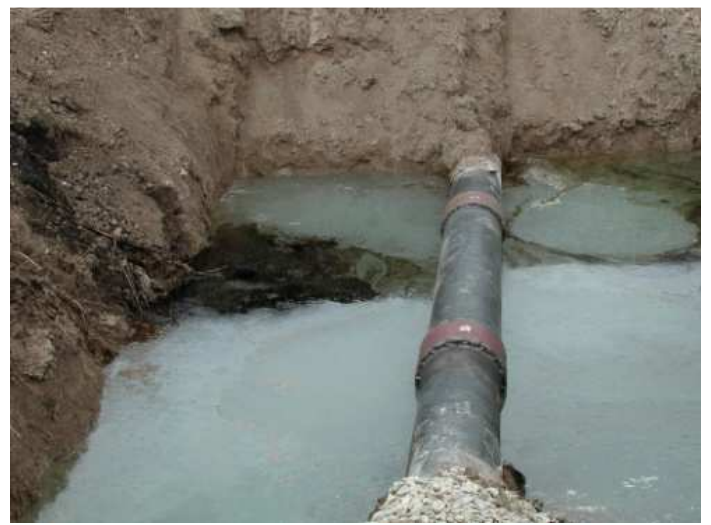

Figure 8. Another view of repaired pipeline, [11] and [12]. 


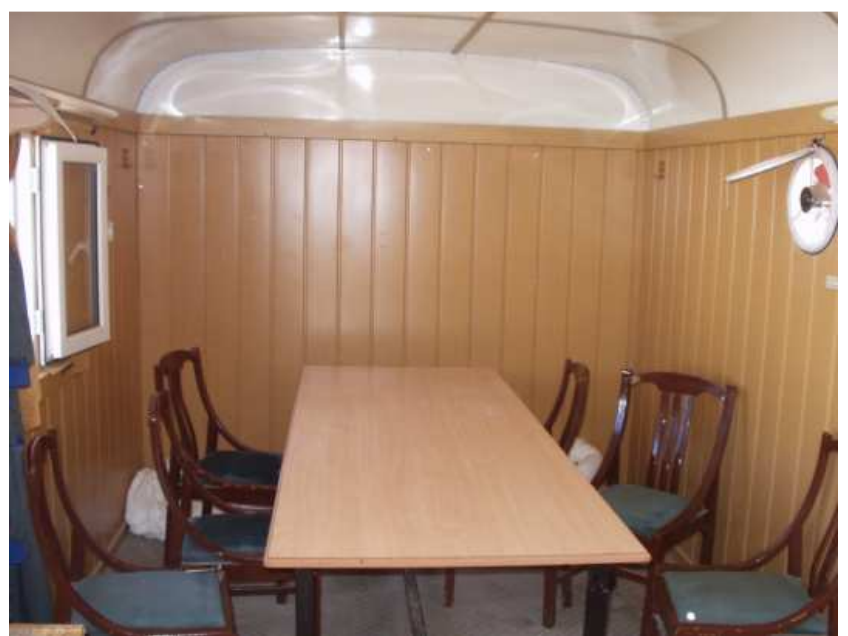

Figure 9. Command room for reponse, [11] and [12].

\subsection{Cleaning Operations}

The oil spread to various areas was located; and necessary actions were taken to recover and prevent oil further spreading, Figures 11-14.

The coves on the shore areas were immediately boomed to prevent spreading oil from these secluded areas. The skimmers were employed to get oil out of water, Figure 15.

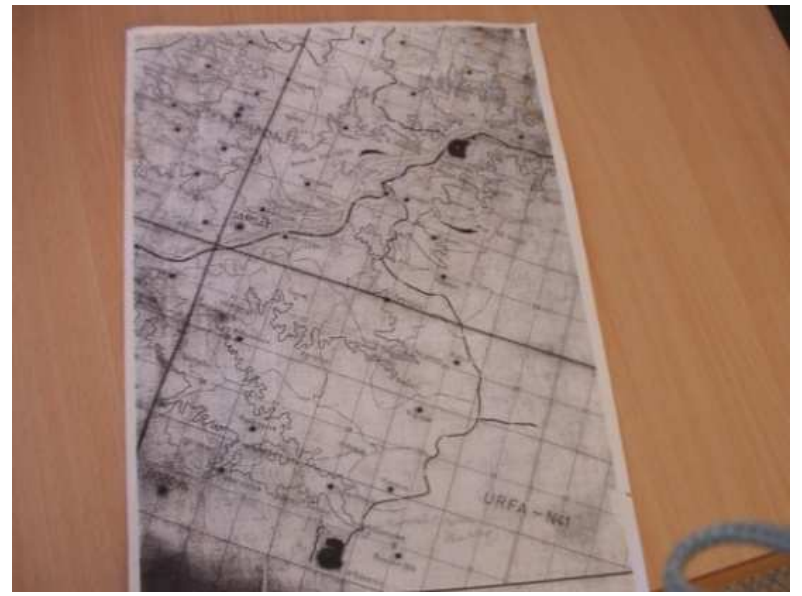

Figure 10. Some sketches, [11] and [12].

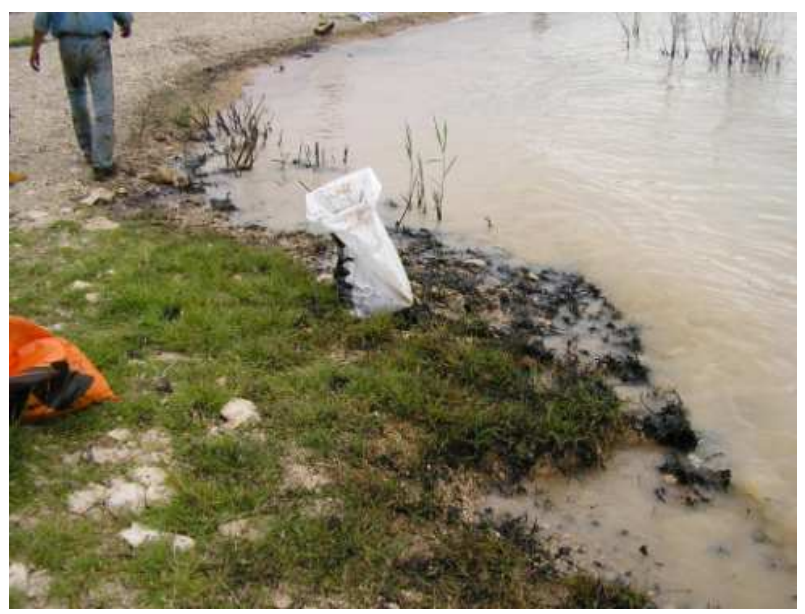

Figure 11. Oily shoreline, [11] and [12].

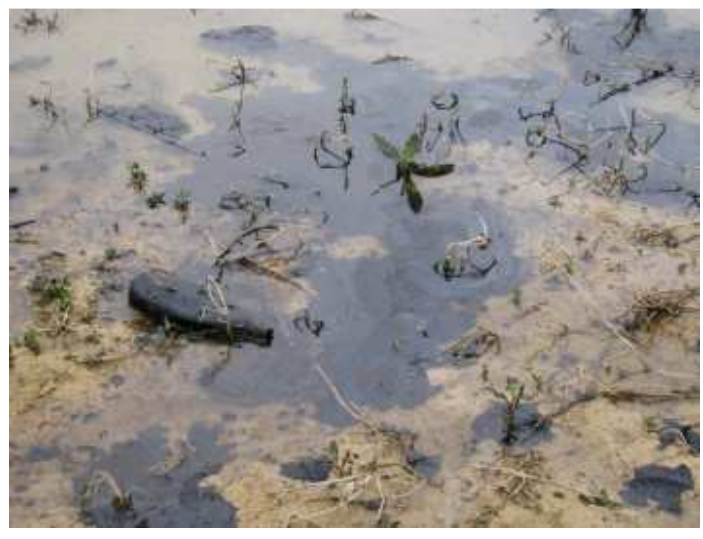

Figure 12. Oil and debris on the water, [11] and [12].

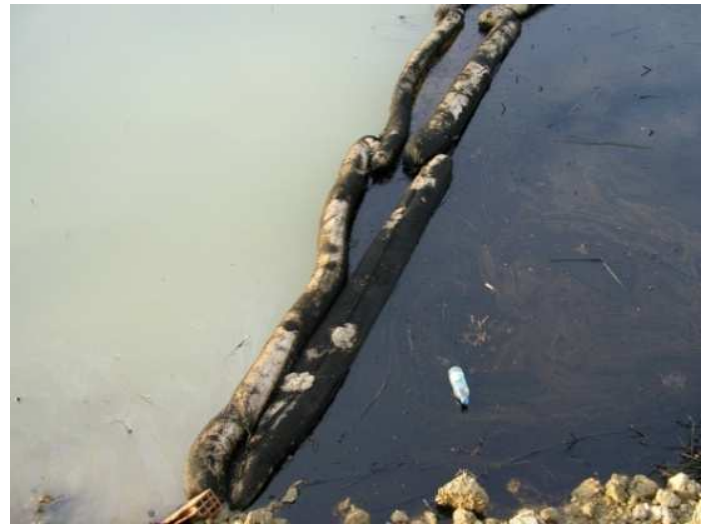

Figure 13. Keeping oil inside a cove, [11] and [12].

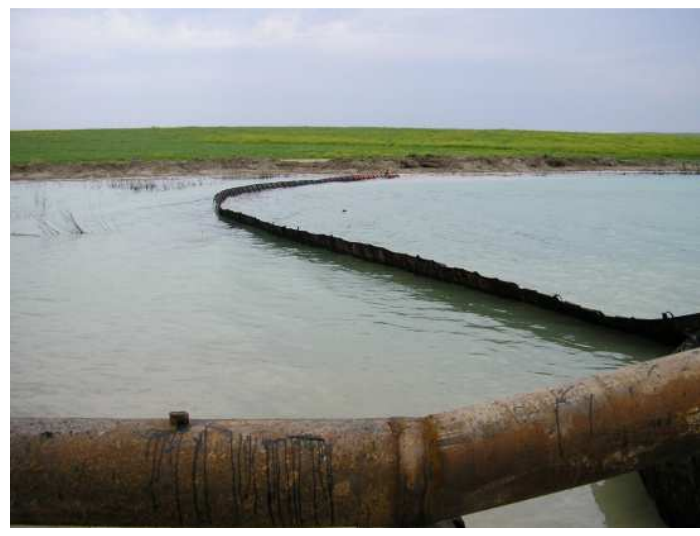

Figure 14. Booming an area to stop further movements of oil, [11] and [12].

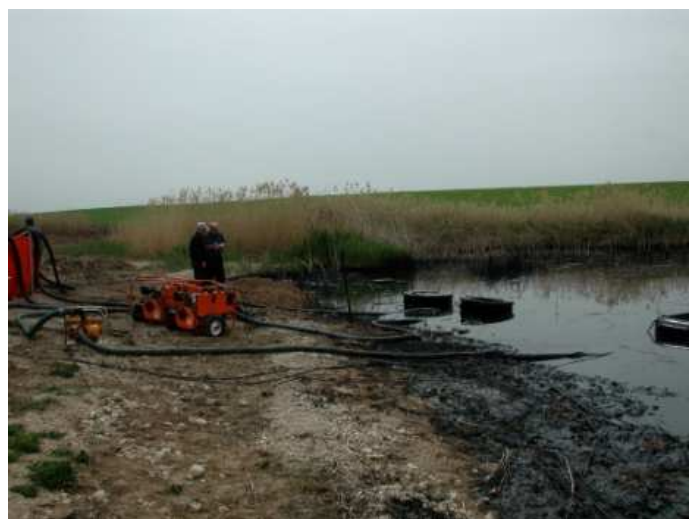

Figure 15. Working skimmer on the oily shoreline, [11] and [12]. 


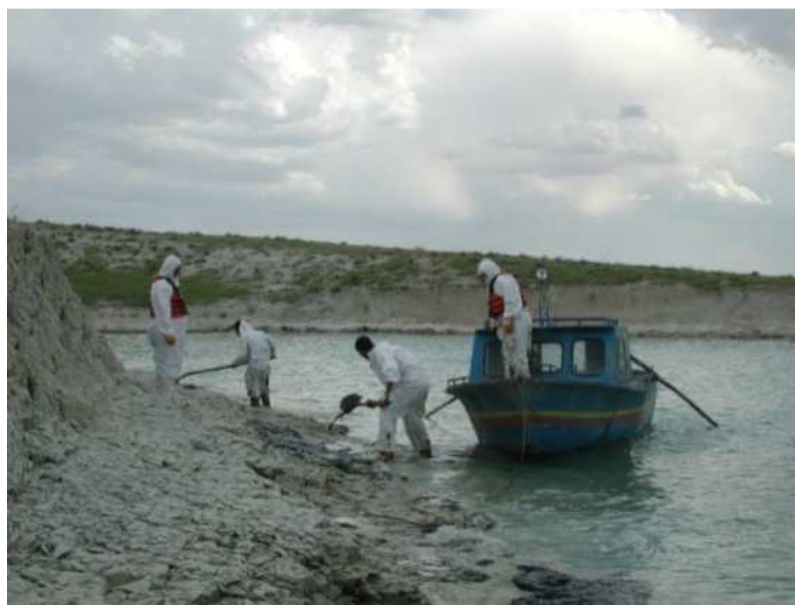

Figure 16. Hand cleaning the shoreline, [11] and [12].

Some areas were very difficult and the only choice was hand cleaning, Figure 16 - 17. The organizing and managing the hand cleaning operation was quite complicated and expensive. This method can only be viable if there is no other choice.

The situation was constantly monitored and discussed, in the command room and field, Figure 18. The decisions in field were quite effective, since they were made through and during combat situations.

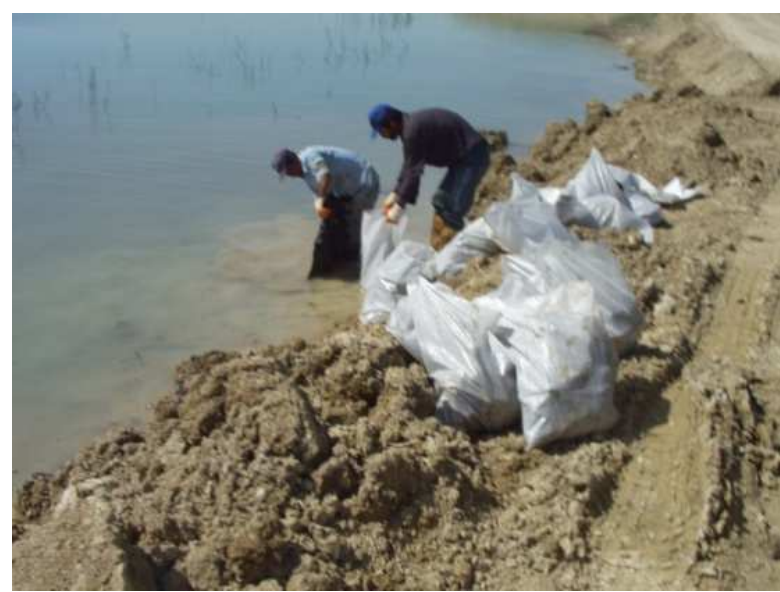

Figure 17. Collecting debris, [11] and [12].

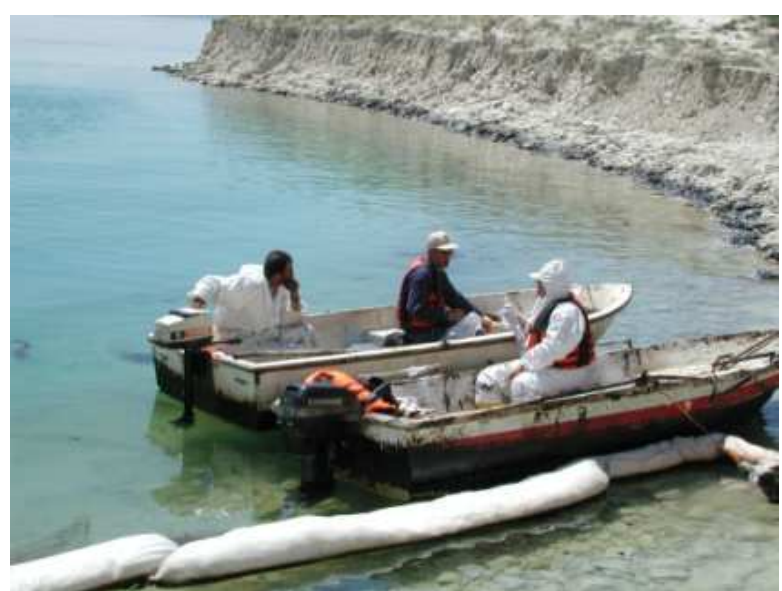

Figure 18. Lunch break and discussions, [11] and [12].
A fishnetted booms were prepared and used to recover oil from water surface. They were used to collect oil on the water; and also in the water column, Figures $19-22$. They were very useful when the modern skimmers were not on the scene.

The oil was still in the environment, Figure 23 and hand cleaning that was a very expensive operation was going on. A hand recovery is presented by Figure 24. Modern and new equipments including a boat skimmer arrived in the accident area; and they were started to use for recovery, Figure 25 - 26.

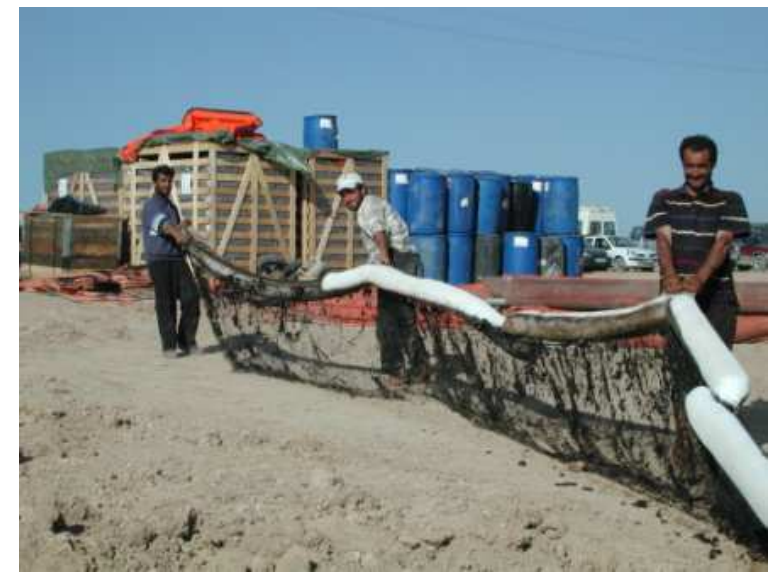

Figure 19. The fishnetted boom prepared for oil collection, [11] and [12].

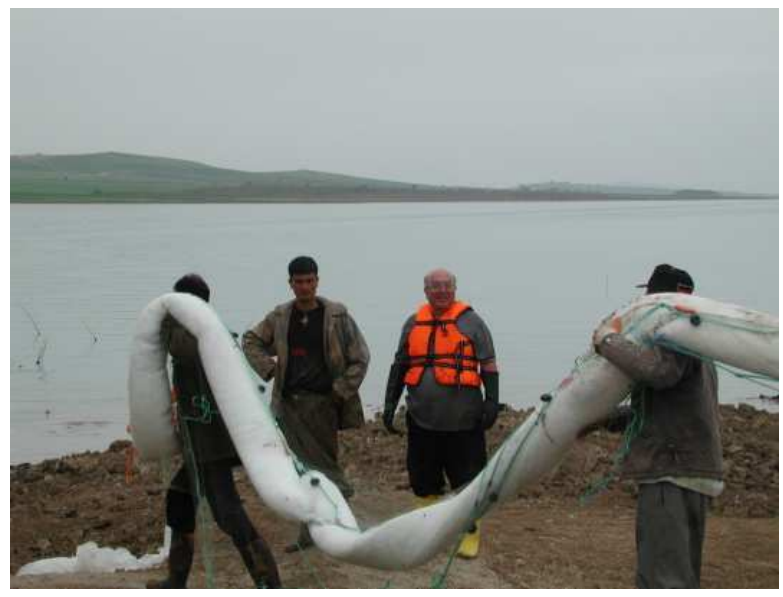

Figure 20.The fishnetted boom to the water for oil collection, [11] and [12].

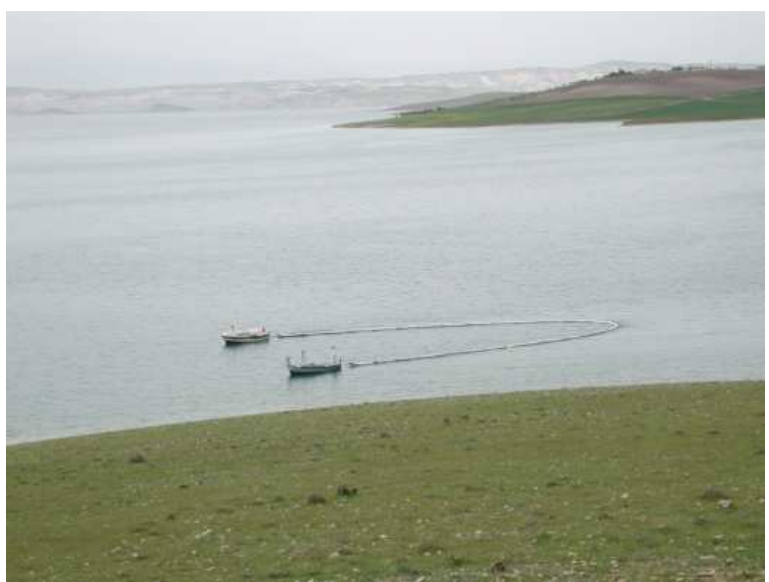

Figure 21. A fishnetted boom in oil recovery from the lake waters, [11] and [12]. 


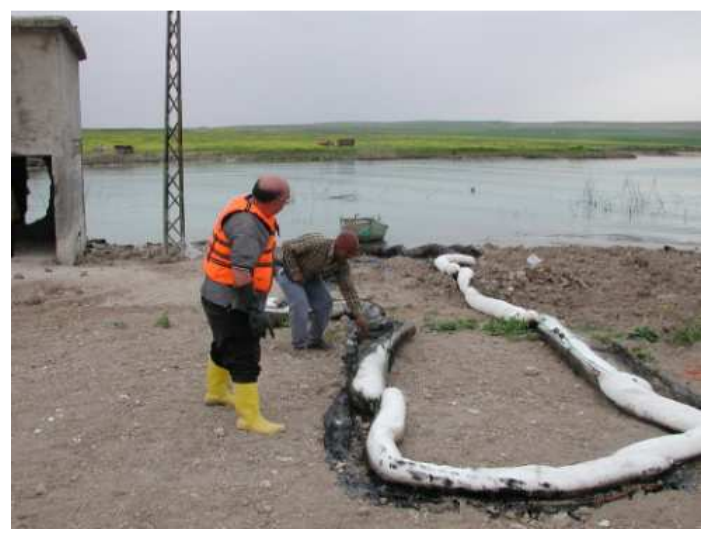

Figure 22. Returning boom with collected oil, [11] and [12].

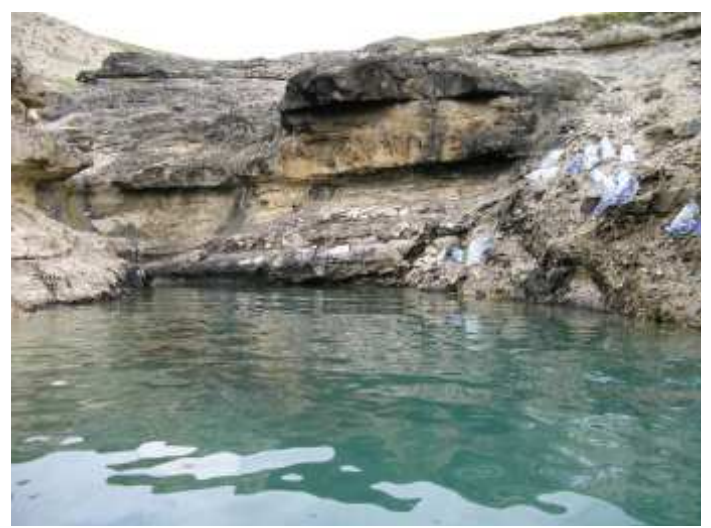

Figure 23. Accumulation of oil on the shore, [11] and [12].

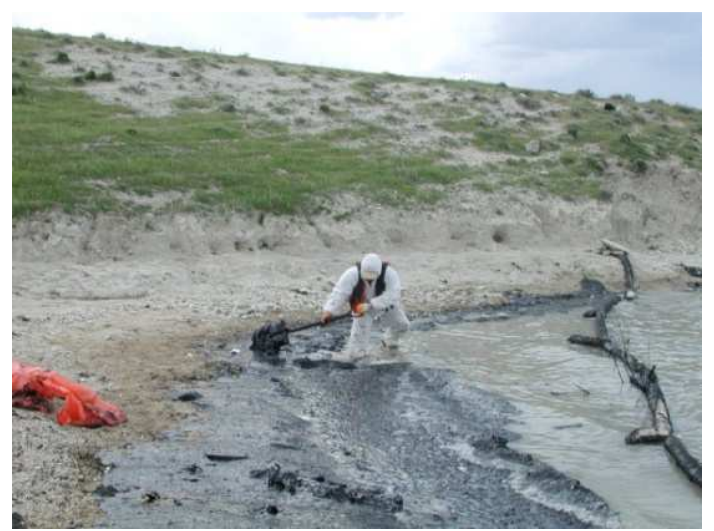

Figure 24. Cleaning the boomed shoreline, [11] and [12].

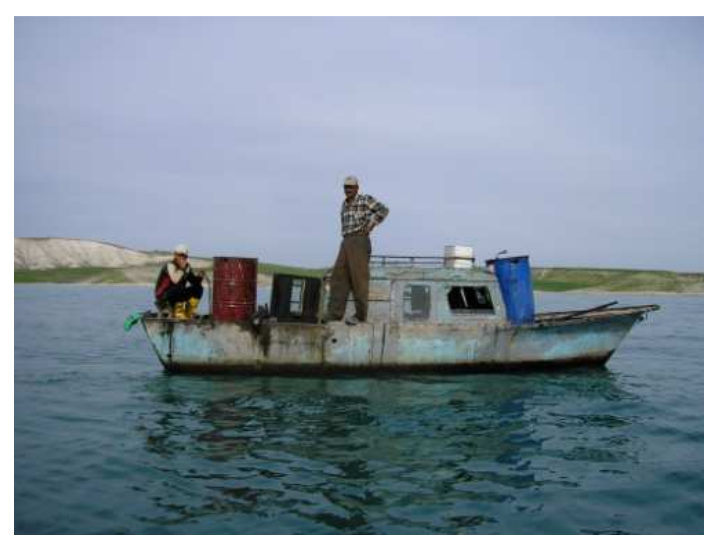

Figure 25. A local recovery boat, [11] and [12].

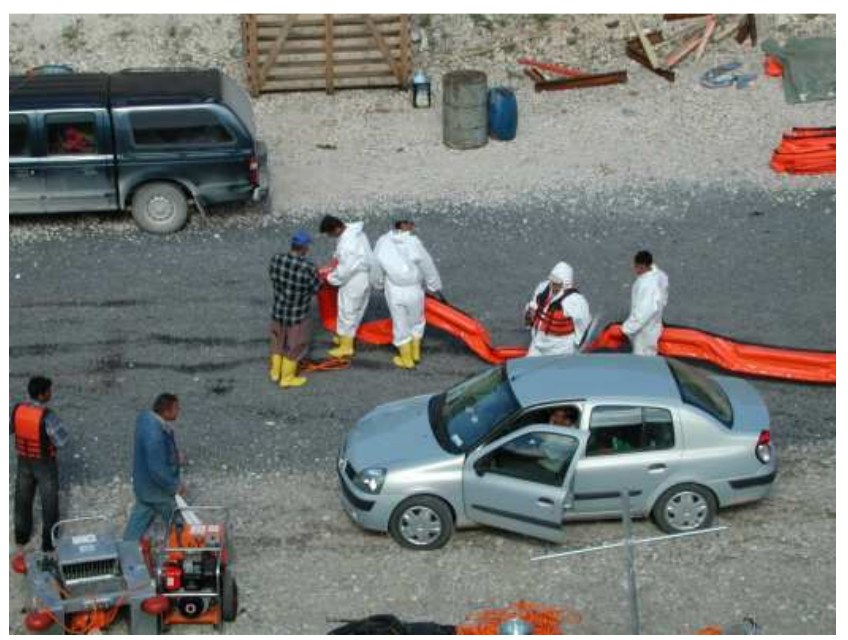

Figure 26. New and modern equipments were in the area, [11] and [12].

The oil collecting materials and debris are presented by Figures 27-30. The equipment and materials must be repaired; and cleaned for reusing and recycling, Figures $31-32$.

Some of the oil spill response equipments are shown by Figures $33-36$.

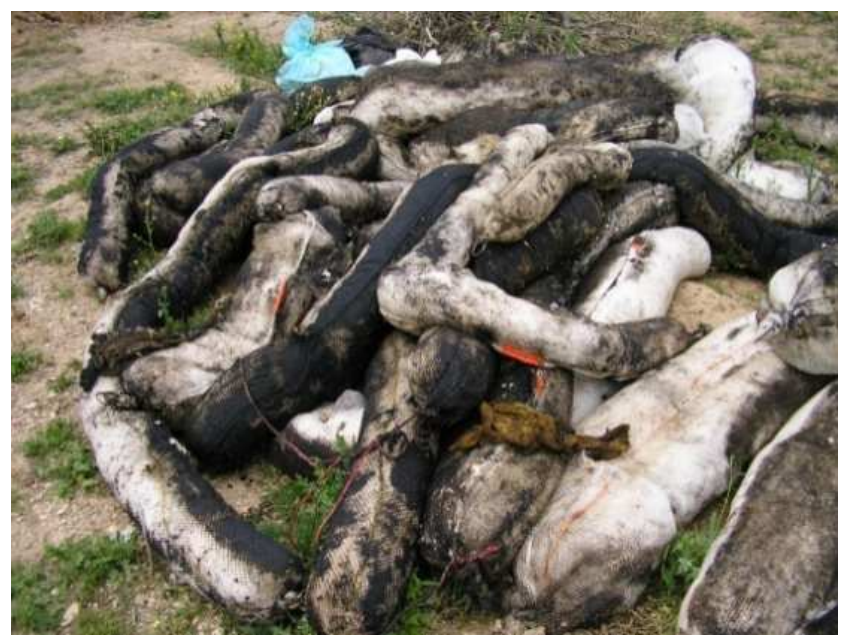

Figure 27. Oily booms, [11] and [12].

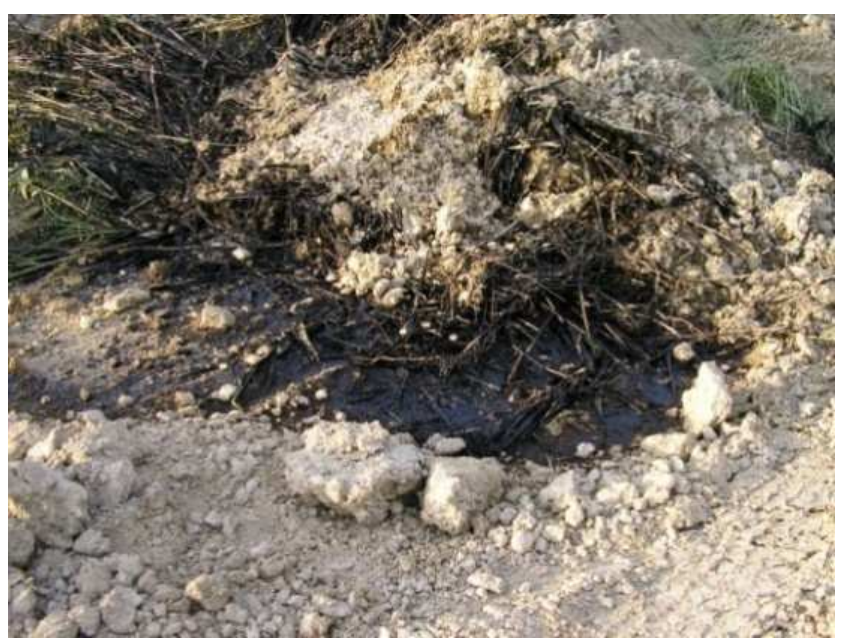

Figure 28. Oiled stones on the shore, [11] and [12]. 


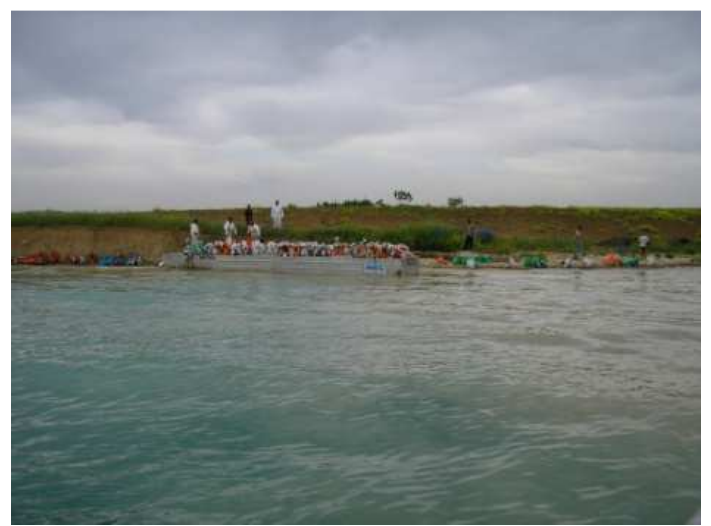

Figure 29. Shoreline and oily debris, [11] and [12].

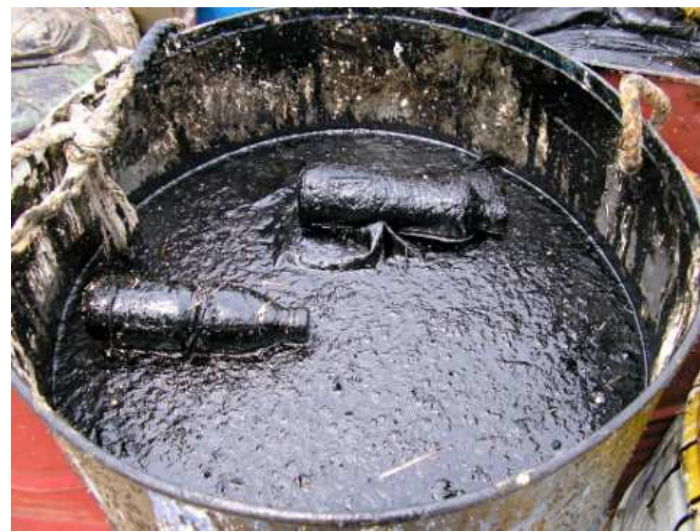

Figure 30. Collected oil, [11] and [12].

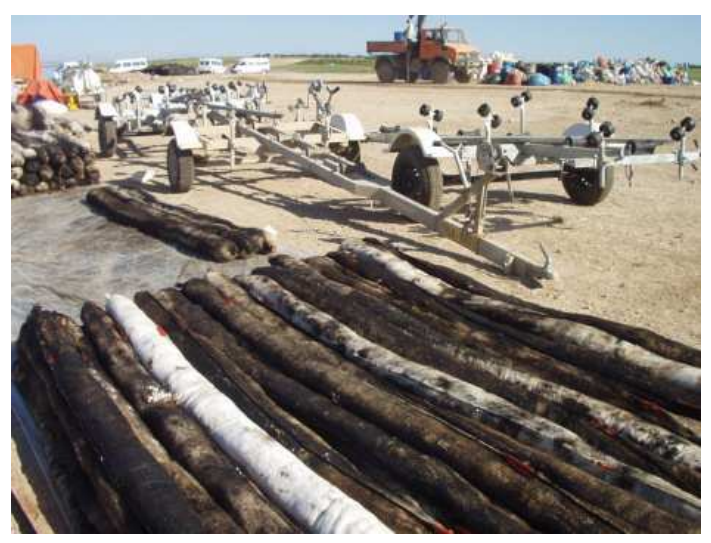

Figure 31. Preparing booms for reuse, [11] and [12].

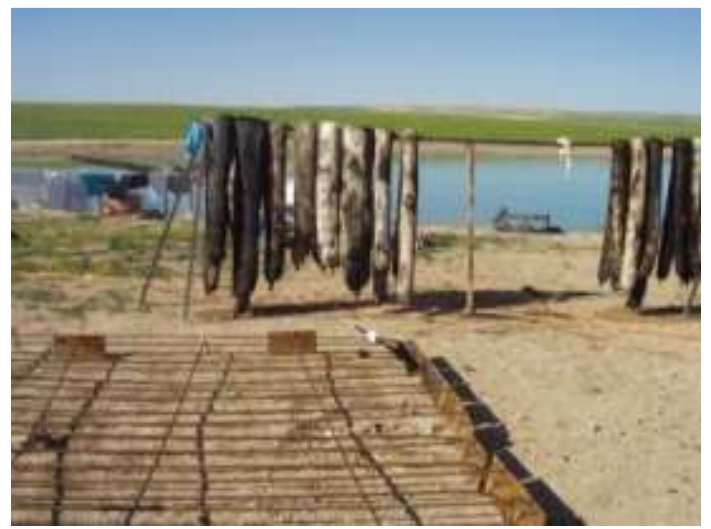

Figure 32. Drying the used booms, [11] and [12].
The equipments are in quite stress, they must be well maintained, repaired and contantly cleaned. There are many different type equipments and they require special expertize and this expertize must be present in the accident area.

The aim is preventing any further contamination in the area during cleaning and recovery activities. The bags, linings and barrels were used with a great care and attention to prevent any damage in the environment.

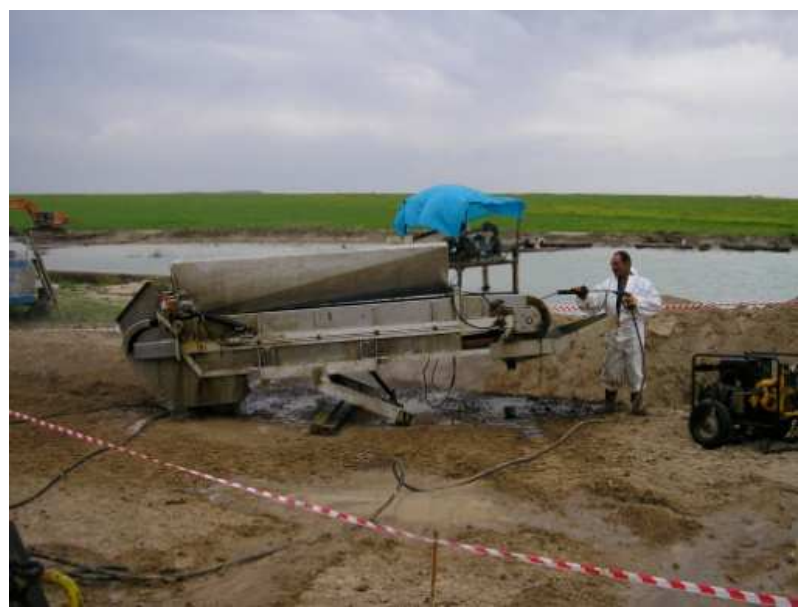

Figure 33. Washing an equipment, [11] and [12].

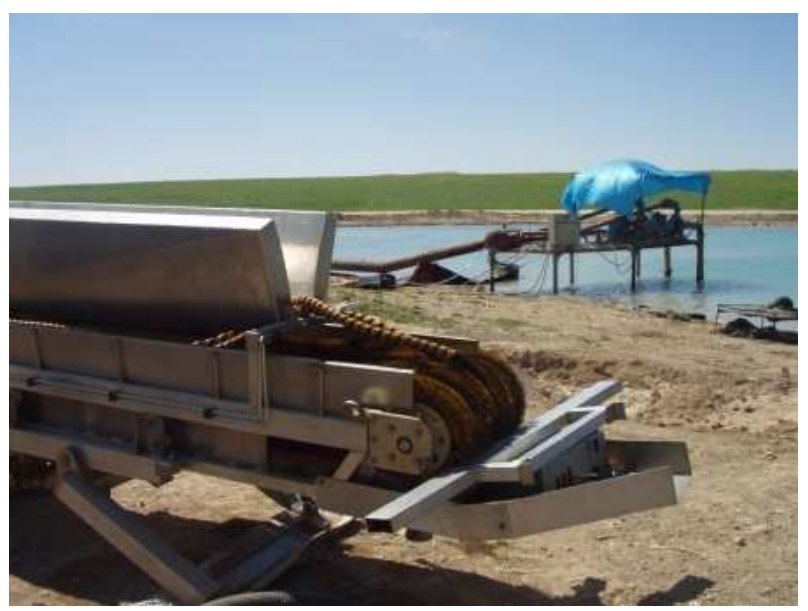

Figure 34. Skimmer on the shore, [11] and [12].

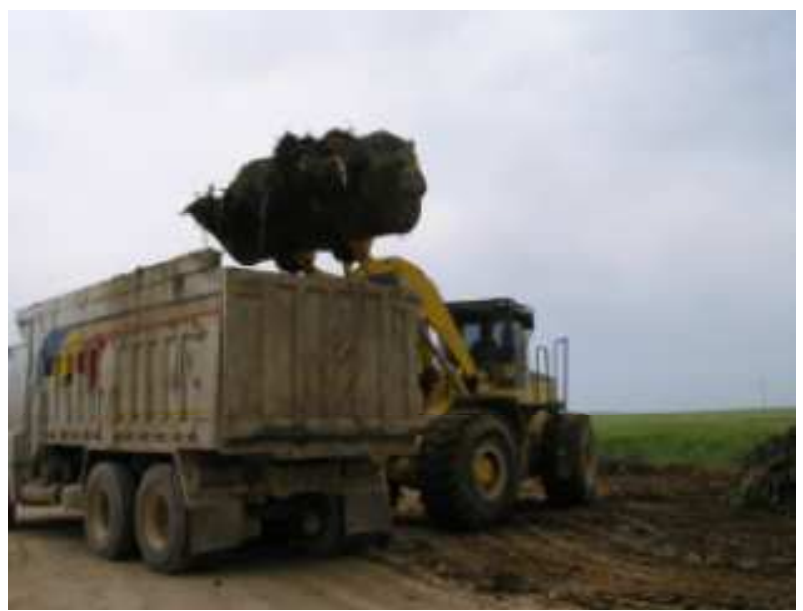

Figure 35. Loading debris, [11] and [12]. 


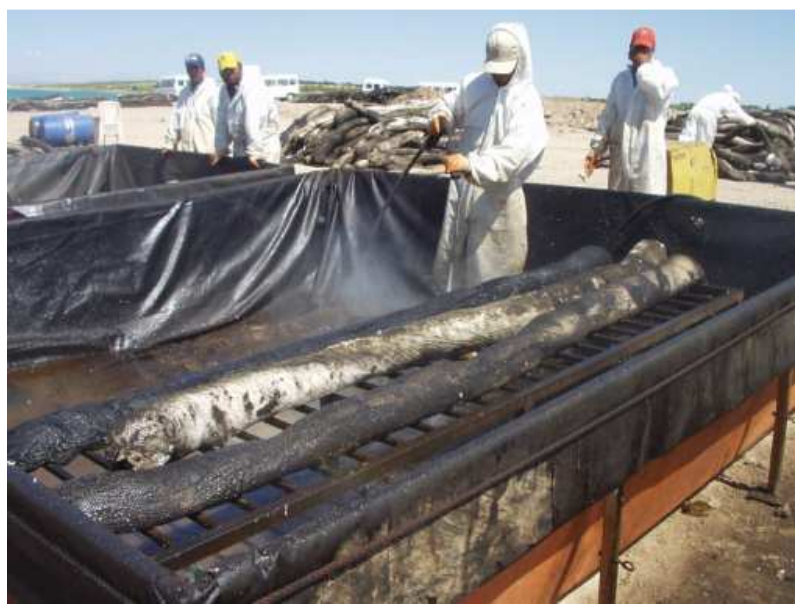

Figure 36. Loading portable storage, [11] and [12].

The collected debris was buried in the lined local and nonlocal pits, Figure 37-46. Debris from which oil can be recoverable was transported to organizations that could treat this material. The oil directly recovered from the spill was sent to a refinery that could process this kind weathered oil.

The debris fields were carefully organized to prevent any further damage to the environment, specially groundwater, surface water and land resources.

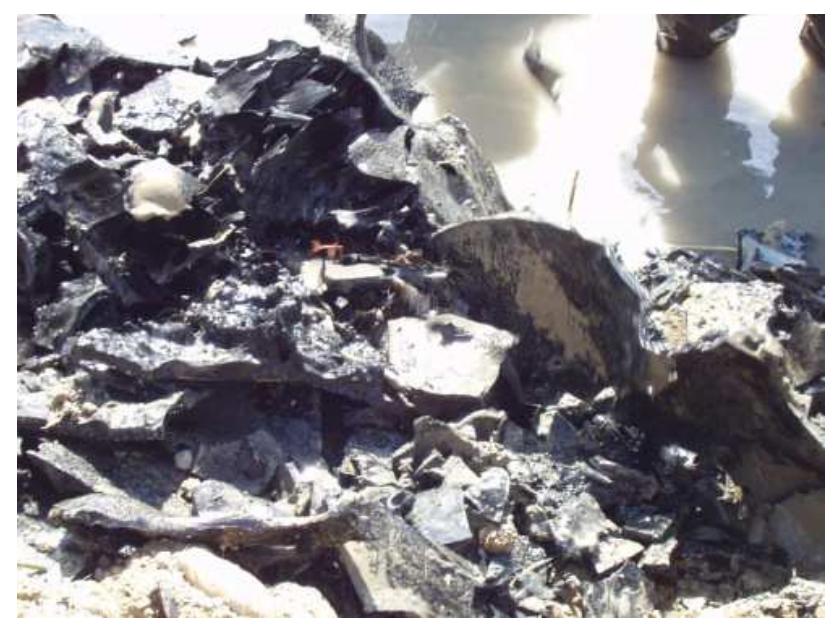

Figure 37. Hardened oil, [11] and [12].

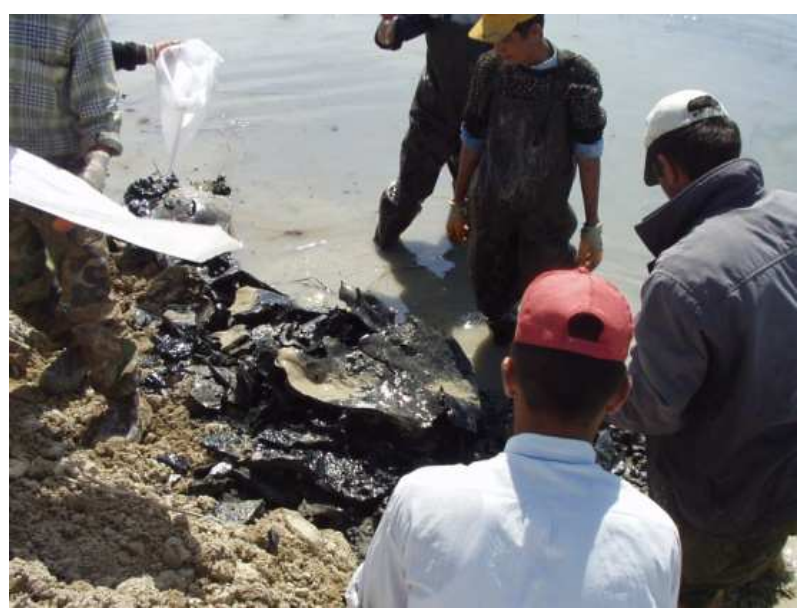

Figure 38. Recovering hardened oil on the shoreline, [11] and [12].

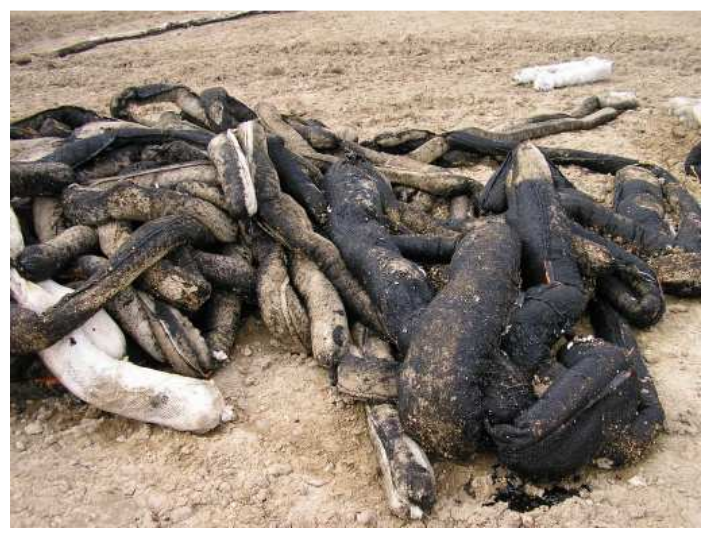

Figure 39. Unusable oily booms on the shore, [11] and [12].

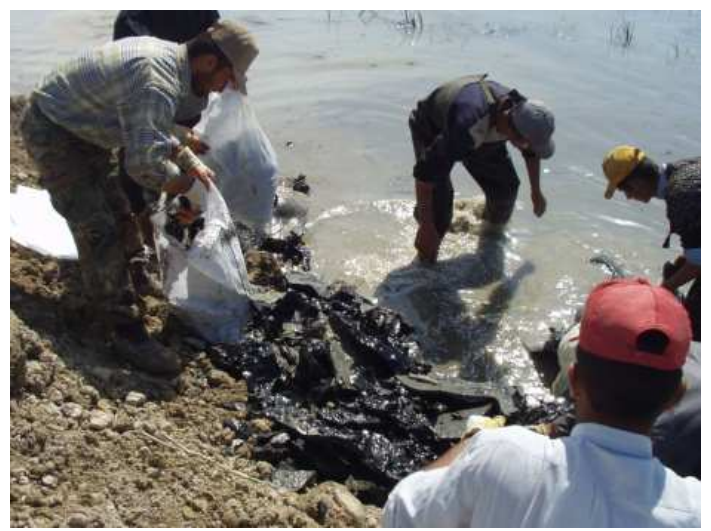

Figure 40. Recovering more oil, [11] and [12].

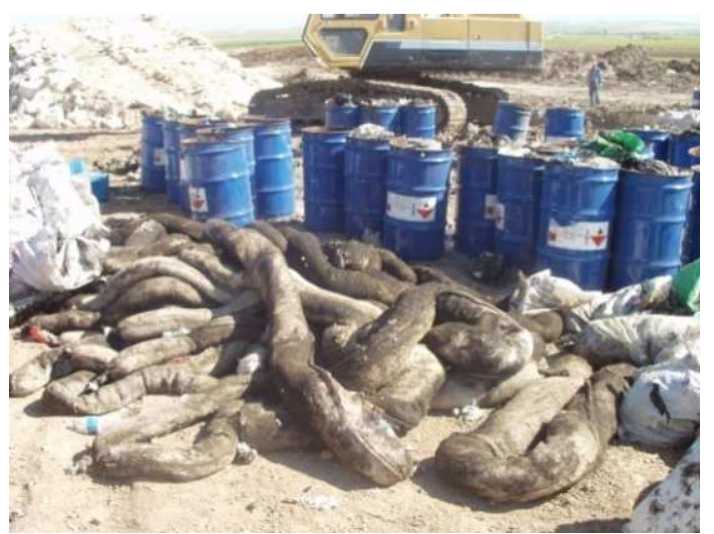

Figure 41. The collection barrels and the oily booms, [11] and [12].

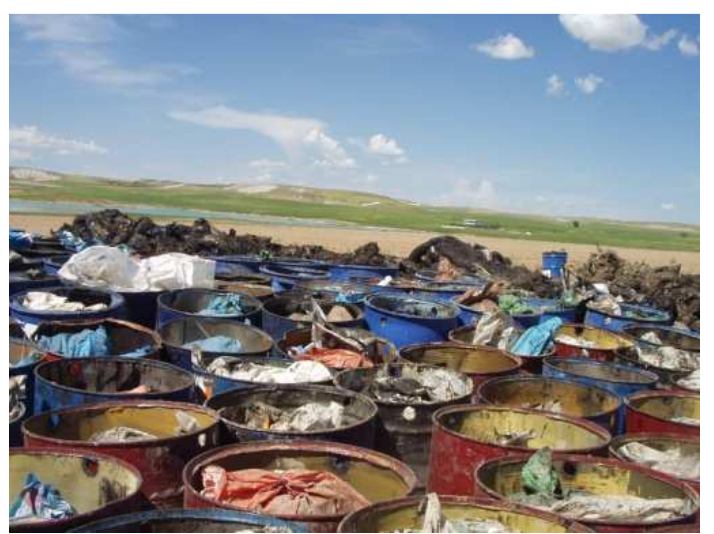

Figure 42. More debris in barrels, [11] and [12]. 


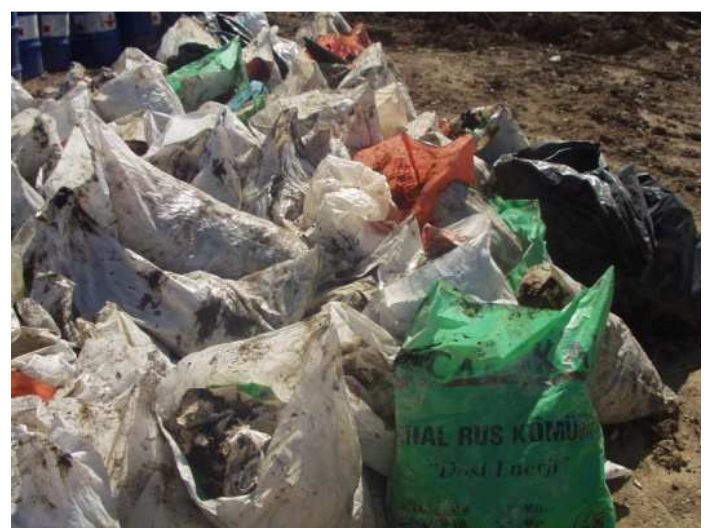

Figure 43. Another pile of debri in bags, [11] and [12].

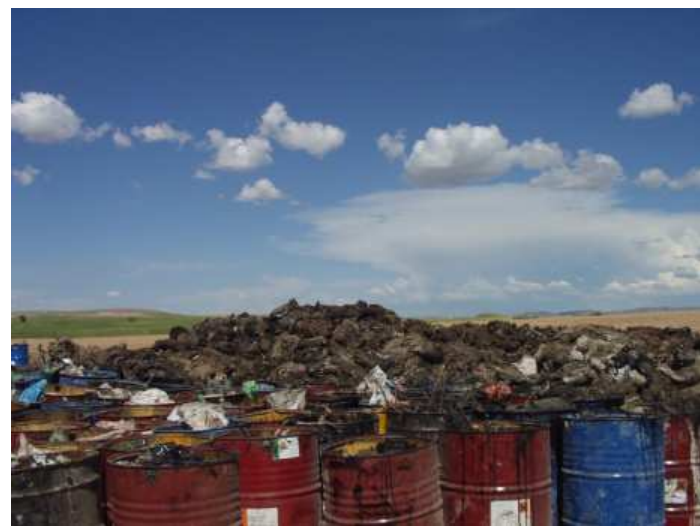

Figure 44. Debris field and barrels, [11] and [12].

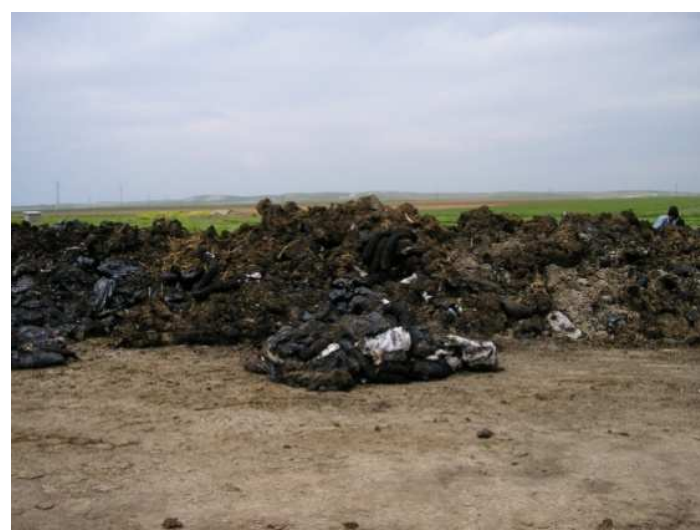

Figure 45. Another view debris storage, [11] and [12].

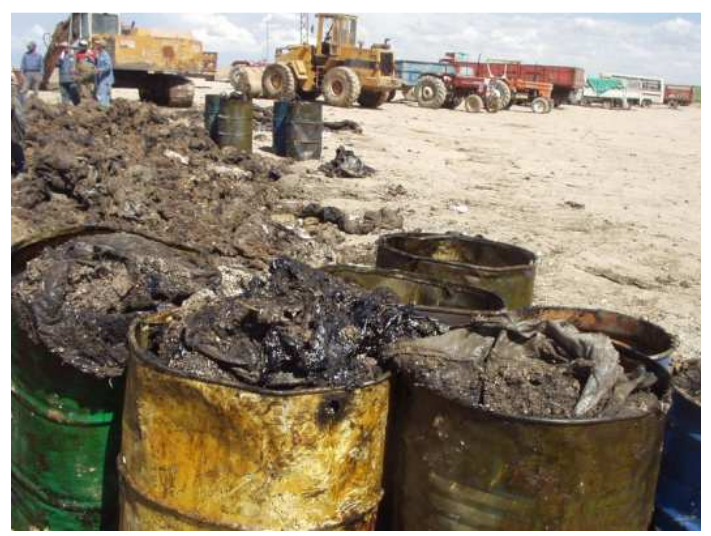

Figure 46. Barrels loaded by debris, [11] and [12].
The selected debris storage area must not interact with any environmental concerns; these are air, water, land and living habitats. In addition, the lining of the debris area must be designed that can take all environmental stresses. The debris area must be organized properly for using in the designated area properly, Figures $47-50$. The post cleaning operations will continue even after careful cleaning operations performed in the area, Figures $51-52$.

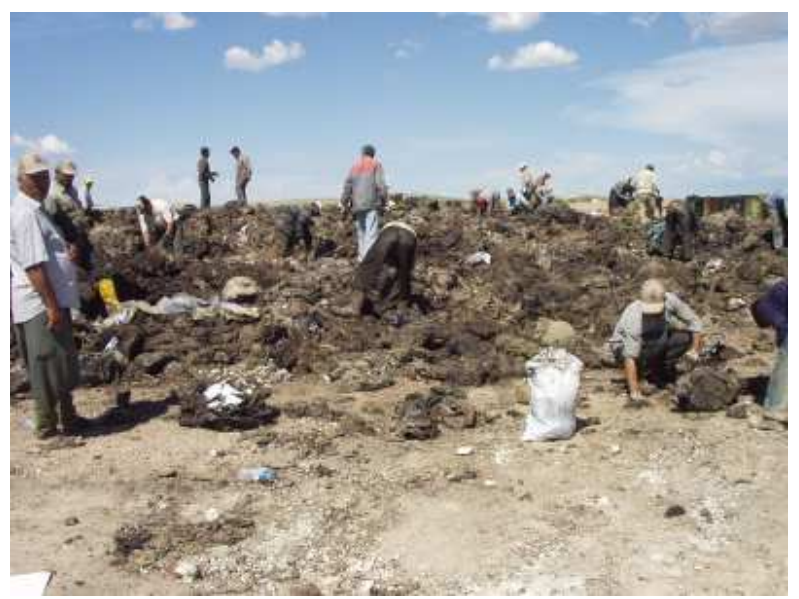

Figure 47. Debris area, [11] and [12].

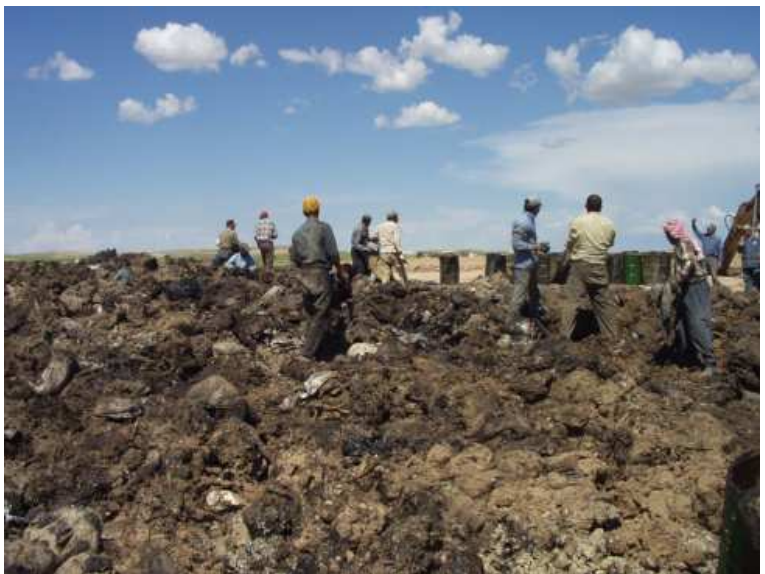

Figure 48. Another view of the debris area, [11] and [12].

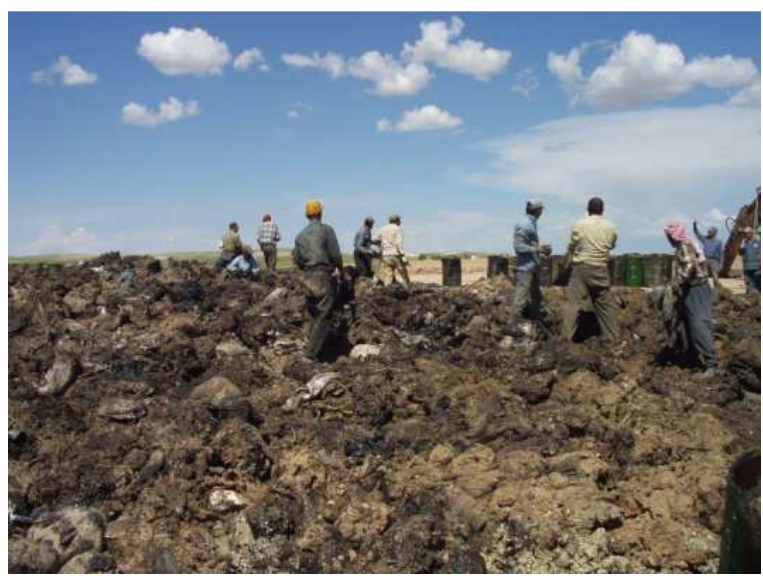

Figure 49. Organizing debris field, [11] and [12] 


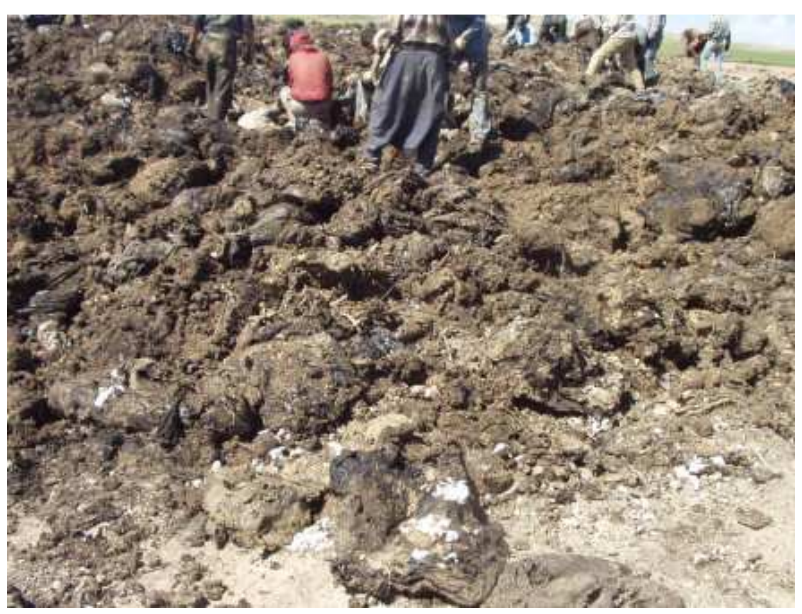

Figure 50. Another view for organizinf debris, [11] and [12].

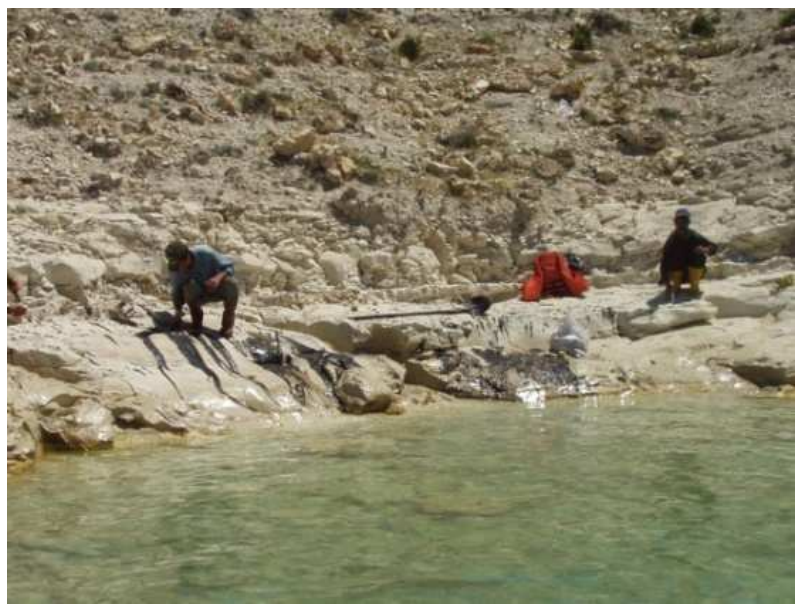

Figure 51. Cleaning stones on the shoreline, [11] and [12].

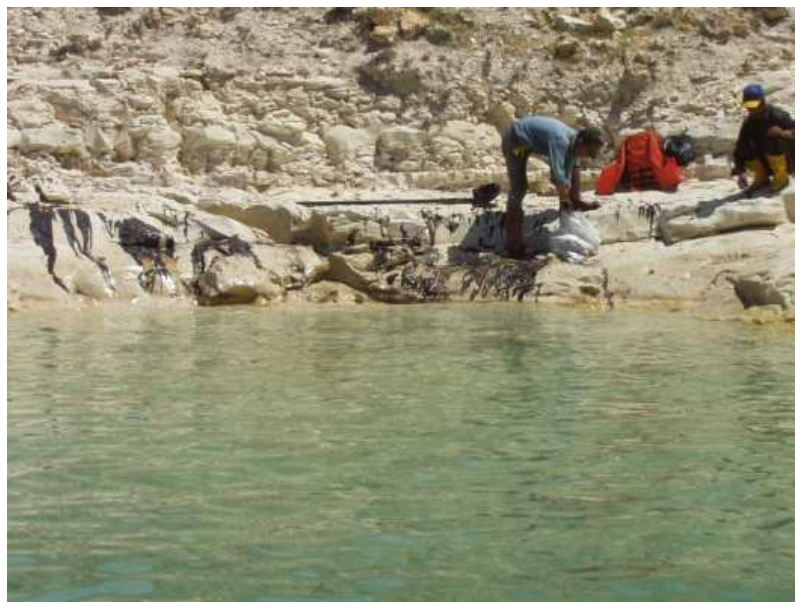

Figure 52. Another view cleaning stones, [11] and [12].

The accident area should be inspected for further cleaning even after cleaning the area,. In these situations, there are always uncleaned areas, Figures $53-58$. These areas must be cleaned further. It is of course, some small oil leftovers will be left to time.

Some bacterial effects and environmental condition will erode leftover hydrocarbons in the area; however some remedies may stay in the region for a long time.

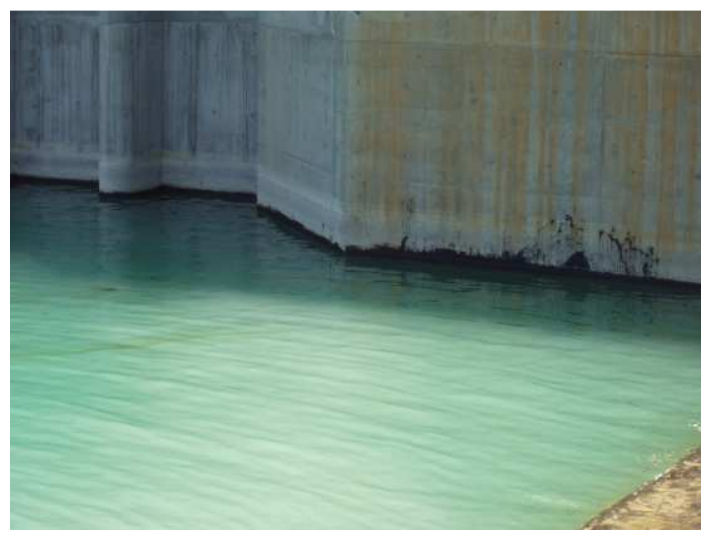

Figure 53. An oiled infrastructure, [11] and [12].

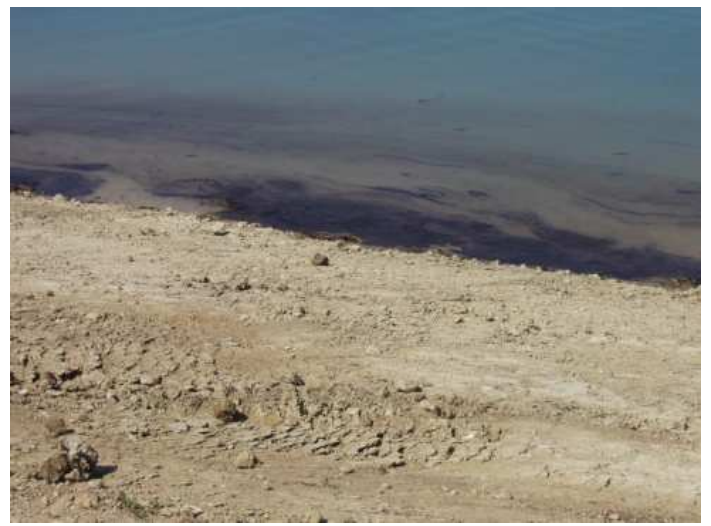

Figure 54. Oil and oil patches on the shoreline, [11] and [12].

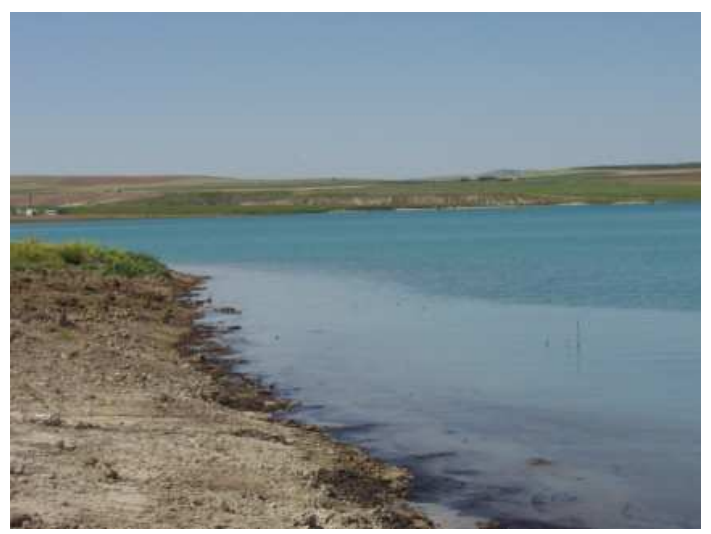

Figure 55. Oil patches on the shoreline, [11] and [12].

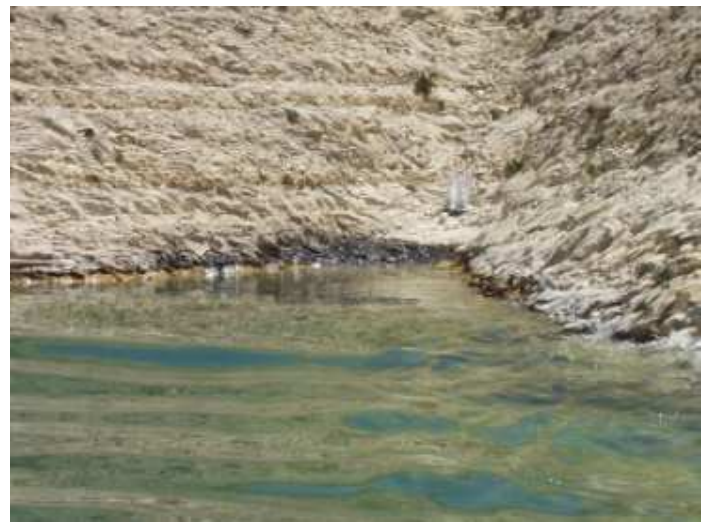

Figure 56. Another oiled shoreline with stones, [11] and [12]. 


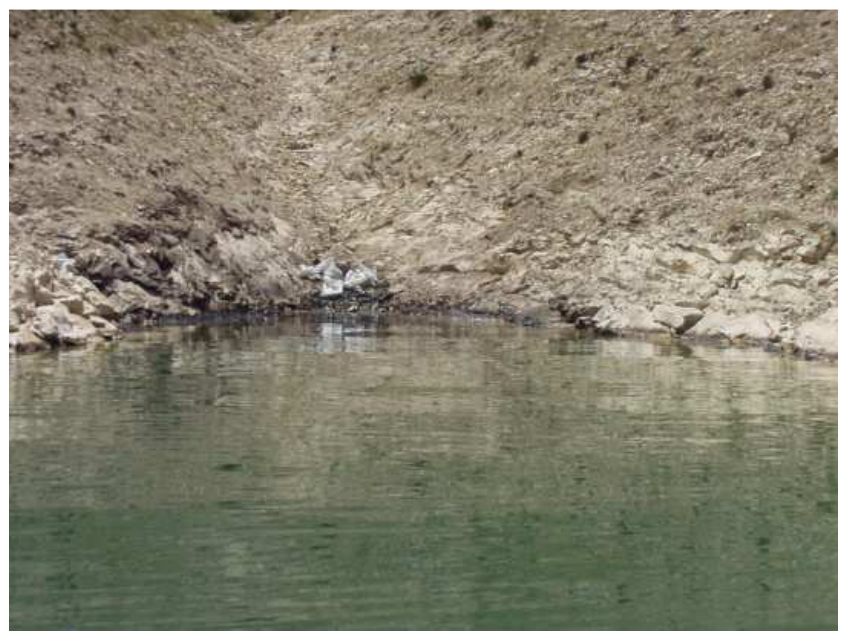

Figure 57. Oiled shoreline with stones, [11] and [12].

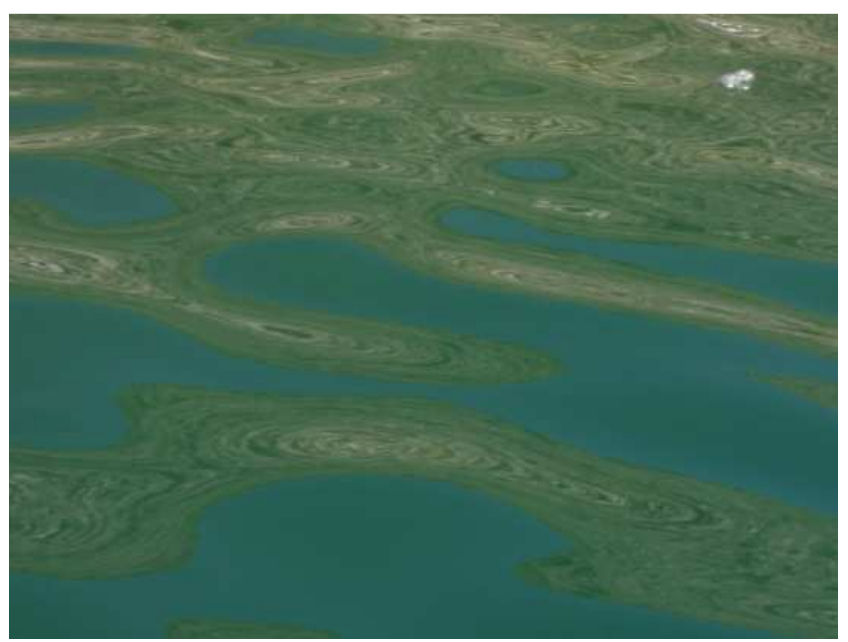

Figure 58. Sheen on the water, [11] and [12].

\section{Conclusion}

The paper is aimed at better understanding of oil spills by presenting photographically real time situations of an oil spill accident; and provides experience to planner and responders. It is almost certain that no spill will be look like and similar to any other previous oil spills, however this paper may and will improve decision making abilities of IC (Incident Command) personnel during actual oil spills. In other words the paper will provide significant experience and feeling to oil spill responders about combat situations.

\section{References}

[1] Huseyin Murat Cekirge. Outlines of an Oil Spill Response Plan (OSRP) for Crude Oil Pipelines. International Journal of Environmental Monitoring and Analysis. Vol. 3, No. 3, 2015, pp. 191-197. doi: 10. 11648/j. ijema. 20150303. 21

[2] Huseyin Murat Cekirge. Quantitative Risk Assessment for Crude Oil Pipelines. International Journal of Environmental Monitoring and Analysis. Vol. 3, No. 3, 2015, pp. 147-153. doi: 10. 11648/j. ijema. 20150303. 16.

[3] Huseyin Murat Cekirge, Omar K. M. Ouda, Ammar Elhassan. A Method for Preparing Environmental Social Impact Assessment (ESIA) of Crude Oil and Gas Pipelines. International Journal of Environmental Monitoring and Analysis. Vol. 3, No. 3, 2015, pp. 154-161. doi: 10. 11648/j. ijema. 20150303. 17

[4] Oil and Gas Pipelines Social and Environmental Impact Assessment, State of the Art, Editor Robert Goodland, Robert Goodland, for IAIA 2005 Conference International Association of Impact Assessment, May 2005.

[5] H. M. Cekirge, "Oil Spills: Determination of Oil Spill Volumes Observed on Water Surfaces", The International Journal of Technology, Knowledge And Society, 8 (6), 17 - 30, 2013.

[6] Huseyin Murat Cekirge. Environmental Risk Assessment Methodology (ERAM) for Oil Pollution. International Journal of Environmental Monitoring and Analysis. Vol. 3, No. 2, 2015 , pp. 91-110. doi: 10. 11648/j. ijema. 20150302. 18

[7] Aristotelis B. Alexopoulos, Managing and assessing oil spills through systematic methods, J. of Middle East Forum, 8, 111-123, 2008.

[8] Lisa Woolgar, Assessing the Increasing Risk of Marine Oil Pollution Spills In China, International Oil Spill Conference Proceedings, Vol. 2008, No. 1, pp. 711-715, May 2008.

[9] NOAA, Environmental Sensitivity Index Guidelines, version 3. 0, NOAA Technical Memorandum, NOS, OR\&R 11, Seattle: Hazardous Response and Assessment Division, National Oceanic and Atmospheric Administration, 129 p. 2002.

[10] The Paris Protocol to the RAMSAR Convention on Wetlands, 1982.

[11] H. M. Cekirge, An Oil Spill on Dam Lake, Maltepe Uni., Internal Rep. 6, Istanbul, 2010.

[12] H. M. Cekirge, Details and Pictures of the Dam Oil Spill, Maltepe Uni., Internal Rep. 8, Istanbul, 2010. 